\title{
The seed germination spectrum of alpine plants: a global meta- analysis
}

\section{Eduardo Fernández-Pascual ${ }^{1}$ (D), Angelino Carta ${ }^{2}$ (D), Andrea Mondoni ${ }^{3}$ (D) Lohengrin A. Cavieres ${ }^{4,5}$ (D), Sergey Rosbakh ${ }^{6}$ (D), Susanna Venn ${ }^{7}$ (D), Annisa Satyanti ${ }^{8}$ (D), Lydia Guja ${ }^{9,10}$ (D), Verónica F. Briceño ${ }^{11}$, Filip Vandelook $^{11}$ (D), Efisio Mattana ${ }^{12}$ (D) , Arne Saatkamp ${ }^{13}$ (D) , Haiyan Bu ${ }^{14}$ (D), Karen Sommerville ${ }^{15}$ (D), Peter Poschlod $^{6}$ (D) Kun Liu $^{14}$ (D), Adrienne Nicotra ${ }^{8}$ (D) and Borja Jiménez-Alfaro ${ }^{16}$ (iD}

\footnotetext{
${ }^{1}$ Departamento de Biología de Organismos y Sistemas, Universidad de Oviedo, Oviedo/Uviéu, Spain; ${ }^{2}$ Dipartimento di Biologia, Botany Unit, University of Pisa, Pisa 56126, Italy;

${ }^{3}$ Department of Earth and Environmental Sciences, University of Pavia, Pavia 27100, Italy; ${ }^{4}$ Departamento de Botánica|Facultad de Ciencias Naturales y Oceanográficas, Universidad de Concepción, Concepción 4070386, Chile; ${ }^{5}$ Chile and Institute of Ecology and Biodiversity (IEB), Santiago, Chile; ${ }^{6}$ Chair of Ecology and Conservation Biology, Institute of Plant Sciences,

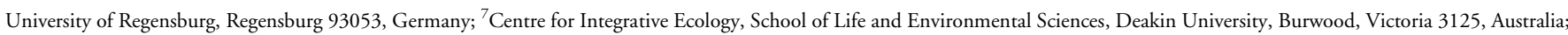

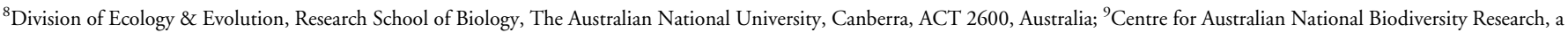
joint venture between Parks Australia and CSIRO, Canberra, ACT 2601, Australia; ${ }^{10}$ National Seed Bank, Australian National Botanic Gardens, Canberra, ACT 2601, Australia; ${ }^{11}$ Meise Botanic Garden, Meise 1860, Belgium; ${ }^{12}$ Natural Capital and Plant Health Department, Royal Botanic Gardens, Kew, Ardingly, RH17 6TN, UK; ${ }^{13}$ Aix Marseille Université, Université

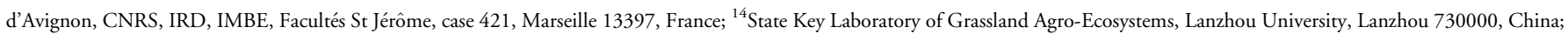

${ }^{15}$ The Australian PlantBank, Australian Institute of Botanical Science, The Royal Botanic Gardens \& Domain Trust, Mount Annan, NSW 2567, Australia; ${ }^{16}$ Research Unit of Biodiversity (CSUC/UO/PA), University of Oviedo, Mieres 33600, Spain
}

Author for correspondence: Eduardo Fernández Pascual Email: efernandezpascual@gmail.com

Key words: alpine, alternating temperature, cold stratification, embryo endosperm ratio, light germination, seed dormancy, seed germination, seed mass.

\section{Summary}

- Assumptions about the germination ecology of alpine plants are presently based on individual species and local studies. A current challenge is to synthesise, at the global level, the alpine seed ecological spectrum.

- We performed a meta-analysis of primary data from laboratory experiments conducted across four continents (excluding the tropics) and 661 species, to estimate the influence of six environmental cues on germination proportion, mean germination time and germination synchrony; accounting for seed morphology (mass, embryo : seed ratio) and phylogeny.

- Most alpine plants show physiological seed dormancy, a strong need for cold stratification, warm-cued germination and positive germination responses to light and alternating temperatures. Species restricted to the alpine belt have a higher preference for warm temperatures and a stronger response to cold stratification than species whose distribution extends also below the treeline. Seed mass, embryo size and phylogeny have strong constraining effects on germination responses to the environment.

- Globally, overwintering and warm temperatures are key drivers of germination in alpine habitats. The interplay between germination physiology and seed morphological traits further reflects pressures to avoid frost or drought stress. Our results indicate the convergence, at the global level, of the seed germination patterns of alpine species.

\section{Introduction}

Alpine environments occur worldwide above the maximum ele vation at which trees can grow naturally (Körner \& Paulsen, 2004; Körner et al., 2011; Testolin et al., 2020). These treeless habitats are characterised by low temperatures, unstable sub strates and short growing seasons (Körner, 2003). Although most alpine plants can reproduce clonally (Körner, 2003), sexual reproduction by diaspores (i.e. seeds, fruits or fruits with extra ovarian structures attached; hereafter 'seeds') is the main strategy to maintain genetic diversity and to colonise suitable new sites in response to environmental changes (Walck et al., 2011). How ever, the short reproductive season of the alpine habitat con strains the phenological timing of flowering, pollination, seed development and seed dispersal. For regeneration by seed to be successful, dispersed propagules must germinate in the most appropriate period to ensure the survival of seedlings (Chambers et al., 1990; Schütz, 2002; Forbis, 2003). The physiological pro cess of seed germination is therefore an essential life stage that must be timed to occur when the environment is favourable for subsequent seedling survival and growth (Poschlod et al., 2013). In alpine habitats, seed germination will also be a crucial test for 
plant populations coping with global change, determining whether they will persist or go into extinction.

Natural selection is expected to favour seed germination requirements that reduce the probability of facing environmental conditions that are not appropriate for seedling survival and growth (Angevine \& Chabot, 1979). Thus, germination is chiefly regulated by environmental cues related to water availability and soil temperature (Bewley et al., 2013). The propagules of many plant species have also developed seed dormancy, by means of which germination is prevented during periods that are only ephemerally favourable, like a short warm spell in the middle of winter (Baskin \& Baskin, 2014). Different degrees of dormancy within a seed population ensure the distribution of seedling emergence across time, a form of bet hedging offspring survival against unpredictable environments (Venable, 2007). Other ger mination cues, such as the response to diurnal alternating tem peratures (Thompson and Grime, 1977) and the need for light or darkness (Carta et al., 2017), allow for a fine scale detection of germination micro niches and safe sites (Jumpponen et al., 1999). Given that current assumptions about the germination ecology of alpine plants are mainly based on local studies, a cur rent challenge is to synthesise, at the global level, the seed ecologi cal spectrum of alpine plants. The seed ecological spectrum (Saatkamp et al., 2019) is defined as a set of seed traits that deter mines the ability of plants to disperse, persist, germinate and establish in different habitats. A major goal for trait based seed ecology is to study the relationships and trade offs between differ ent aspects of the seed ecological spectrum (Saatkamp et al., 2019), such as the physiological drivers of germination versus key morphological traits like seed mass (Moles et al., 2005) and the embryo to seed ratio (Vandelook et al., 2012).

Traditionally, alpine species have been described as having seeds with physiological dormancy, which is a type of dormancy that is caused by the seed's internal balance of phytohormones and requires a long exposure to dormancy alleviating treatments to be terminated (Schwienbacher et al., 2011; Sommerville et al., 2013; Baskin \& Baskin, 2014). This physiological dormancy would prevent precocious germination of recently dispersed seeds during autumn, when appropriate conditions are not likely to persist for more than a few weeks or days (Meyer \& Monsen, 1991). A requirement for cold stratification to alleviate dormancy allows seeds to sense the snow season, thereby postponing germi nation to a more favourable period for seedling survival and development. Thus, it can be expected that a cold stratification period is a requirement for seed germination in alpine plants. One of the first experiments on this topic was conducted by Söyrinki (1938), who showed how the storage of arctic-alpine species at winter temperatures (i.e.cold stratification) increased seed germination in most species. Nonetheless, Amen (1966) later suggested that cold stratification was not a requirement for seed germination of alpine species from different mountain ranges in the USA, a finding that was supported by subsequent studies (Sayers et al., 1966; Marchand \& Roach, 1980; Kaye, 1997). More recently, research on Australian alpine plants found that a cold stratification period only increased germination in half of the species tested (Sommerville et al., 2013; Hoyle et al.,
2015). Cold stratification increased seed germination over a range of temperatures in most of the species studied in the alpine zone of Japan (Shimono \& Kudo, 2005). Along an elevational gradient in the central Chilean Andes, cold stratification was an important requirement for seed germination in species from lower elevations, while species from higher sites did not germi nate after a single period of cold stratification (Cavieres \& Sierra Almeida, 2018). Finally, in a comparative study on germination of unstratified seeds from different habitats of the Austrian Alps, species from alpine grasslands had the lowest final germination proportion, suggesting that they had the highest level of dor mancy (Margreiter et al., 2020).

Seed dormancy is not the only trait that can prevent, in prac tice, autumn germination. Early studies on the germination ecology of alpine plants demonstrated that, in most species, recently dispersed seeds require relatively high temperatures for germination (Söyrinki, 1938; Bliss, 1958; Amen, 1966; Billings \& Mooney, 1968). Warm cued germination has been consid ered as an adaptation to prevent seed germination at the time of seed dispersal (autumn) when temperatures are relatively low and there is a high risk of frost (Cavieres \& Arroyo, 2000). Indeed, germination of alpine seeds tends to occur after winter, mainly in early summer (Körner, 2003; Mondoni et al., 2015). In recent times, an increasing number of studies have reported that fresh seeds of some alpine plants can also germinate at cool incubation temperatures or during cold stratification treatments (Schwienbacher et al., 2011; Hoyle et al., 2015; Fernández Pas cual et al., 2017a; Cavieres \& Sierra Almeida, 2018). This cold cued germination could be an adaptation to germinate under snow or during snowmelt, which could presumably allow seedlings to develop a deeper root system before topsoil desicca tion in summer (Kammer \& Möhl, 2002), or to attain an opti mal size for overwintering (Billings \& Mooney, 1968). Yet, the generality of warm cued germination across different alpine regions and habitats has never been studied systematically, and the relative importance of cold stratification versus warm cued germination remains unclear. A central question is whether physiological seed dormancy plays a relevant role in postponing alpine germination during autumn and winter, or whether the warm cued germination is enough to prevent germination under cool autumn temperatures. The response to this question becomes pertinent under a warming climate, which could result in nondormant seeds germinating readily in autumn. Nondor mant seeds could possibly have an advantage as the growing sea sons become longer, if seedlings have enough time to grow and become sufficiently large to survive the winter snow season. Potentially, having a nondormant or less dormant seed could be a better strategy for alpine plants to thrive under future climate (Verdú \& Traveset, 2005; Mondoni et al., 2015). However, we might also expect that seedlings from these species will be exposed to frost damage if snow starts to melt earlier and insula tion during winter disappears (Venn et al., 2013) and therefore mechanisms that enable diverse germination timing (i.e. low germination synchrony) may be favoured.

Besides patterns of seed dormancy and germination tempera ture, the response of alpine seeds to diurnal alternating 
temperatures and light can provide further information on their capacity to detect fine scale environmental cues. Fluctuations of diurnal temperature decrease with increasing burial depths and the depth profile of this decrease depends on soil type, vegetation cover and snow (Thompson and Grime, 1977; Van Assche \& Vanlerberghe, 1989; Saatkamp et al., 2011). Solar irradiance in physiologically significant quantities penetrates only the first mil limetres of the soil (Tester \& Morris, 1987). Therefore, the response to alternating temperatures and light can indicate to seeds whether they are buried deep in the soil, in rock crevices or under snow. The depth of seed burial is crucial for seedling emer gence, as small seeds lack the resources to survive until they reach the soil surface (Bond et al., 1999). A study of 445 species from the Qinghai Tibet plateau found that species from high elevation alpine meadows did not show a significant response to diurnal temperature oscillations (Liu et al., 2013). This is intriguing given that alpine habitats typically have a strong day/night cli matic variation during the growing season. Regarding light and darkness, some local studies have found alpine species to have a preference for germinating in light (Densmore, 1997; Mondoni et al., 2009). This trait is linked to the creation of a persistent soil seed bank (Venn \& Morgan, 2010; Jaganathan et al., 2015) which may be advantageous in the temporally and spatially unpredictable alpine environments (Arroyo et al., 1999; Cavieres \& Arroyo, 2001). Indeed, persistent alpine soil seed banks are more frequent than previously supposed, as consistently reported in recent years (Venn \& Morgan, 2010; Hoyle et al., 2013; Jaganathan et al., 2015). Nevertheless, other alpine species seem to prefer germination in darkness (Schwienbacher et al., 2011), which may be interpreted as a strategy for detecting safe sites in rock crevices (Arslan et al., 2011). Although some germination studies report laboratory experiments conducted with constant and alternating temperatures, or light and dark conditions, they are very much case dependent, and therefore it is difficult to eval uate whether these factors show a consistent pattern across global alpine ecosystems.

In this work, we make a global collection of primary germina tion data from laboratory experiments conducted with seeds of alpine plant species from extratropical regions. The assembled dataset represents eight seasonal alpine regions belonging to four continents. We perform a meta analysis of this dataset to investi gate the germination response of alpine plants to key environ mental factors: dormancy alleviating treatments (cold stratification, $\mathrm{GA}_{3}$ and scarification), average germination tem perature, diurnal alternating temperatures and light (Bewley et al., 2013; Baskin \& Baskin, 2014). Given the heterogeneity of alpine species lineages adapted to different regions, we account for the shared evolutionary history using a phylogenetic compara tive approach (Garamszegi, 2014). We further analyse the rela tionships between germination ecology and two morphological traits that are key drivers of the seed ecological spectrum: seed mass and the embryo to seed ratio (Saatkamp et al., 2019). Our main aim in conducting this work is to test the consistency of general assumptions about the influence of major environmental cues on seed germination of alpine plants. Specifically, we deter mined at the global scale whether alpine seeds: (1) have physiological dormancy; (2) require cold stratification to alleviate dormancy; (3) need relatively warm temperatures to germinate; (4) do not require alternating temperatures for germination; and (5) respond positively to light. To understand the ecological con straints of our meta analysis on alpine species pools, we com pared the germination responses of strict alpine species (that occur predominantly above the treeline) and generalist species (that occur above the treeline but also at lower elevations). We can expect that the former group will show a more convergent alpine germination syndrome, while the latter will be more plas tic in their response.

\section{Materials and Methods}

\section{Data collection}

We conducted a meta analysis of primary data (Mengersen et al., 2013), a type of meta analysis which consists of pooling together original data from different local studies to synthesise their con clusions at the global level. All data processing, analysis and manuscript production was performed in $R$ ( $\mathrm{R}$ Core Team, 2020). The original data, plus $R$ code for the analysis and cre ation of the manuscript using R/MARKDOWN, can be accessed at the article's GitHub repository (see Data Availability statement). To gather data, we contacted research groups that had performed experiments on seed germination of alpine plants, asking them to provide raw data from laboratory germination experiments. The submitted data had to report the studied species, the germination treatments, the number of seeds sown, and the number of seeds germinated. We received data (Table 1) on species from the Cantabrian Mountains of Spain, the European Alps, the Italian Apennines, the Northern Caucasus, the Qinghai Tibet Plateau of China, the Chilean Andes and the Australian Alps. We also received data on European Alpine species from ENSCOBASE, the database of the European Native Seed Conservation Network ENSCONET (http://enscobase.maich.gr/index.tml).

We standardised the species names according to The Plant List (The Plant List, 2013) using the package TAXONSTAND (Cayuela et al., 2019) in R. For each species, we recorded its elevation range from local floras (Hegi, 1906; Pignatti, 1982; Castroviejo, 1987; Brach \& Song, 2006; Parolly \& Rohwer, 2019), catalogues (Rodríguez et al., 2018) and herbaria (Australian National Herbarium, https://www.anbg.gov.au/cgi bin/anhsir). We used the elevation ranges: (1) to remove from the dataset outlier species that do not grow above the treeline; and (2) to classify the rest of the species as strict alpine (i.e. species that grow predomi nantly above the treeline) or generalist (i.e. species that can grow above the treeline but also in the lowlands). For each species, we compiled three additional traits: seed dormancy class, seed mass and embryo : seed ratio.

We classified the species in seed dormancy classes following Baskin \& Baskin (2014) and Rosbakh et al. (2020a), using five categories: physiological (germination prevented by the seed's internal balance of phytohormones), morphological (germination prevented by an embryo which is underdeveloped at the time of dispersal), morphophysiological (both physiological and 
Table 1 Description of the datasets contributing primary data to this meta analysis. The number of germination records, number of species and number of strict alpine species are given.

\begin{tabular}{|c|c|c|c|c|}
\hline Source & Coverage & Records & Species & Strict \\
\hline V. F. Briceno, unpublished & $\begin{array}{r}\text { Chilean } \\
\text { Andes }\end{array}$ & 236 & 25 & 5 \\
\hline Bu et al. $(2007,2008)$ & $\begin{array}{l}\text { Qinghai } \\
\text { Tibet }\end{array}$ & 1766 & 242 & 68 \\
\hline $\begin{array}{l}\text { Cavieres \& Arroyo (2000), } \\
\text { Cavieres \& Sierra Almeida } \\
(2018)\end{array}$ & $\begin{array}{c}\text { Chilean } \\
\text { Andes }\end{array}$ & 804 & 31 & 6 \\
\hline ENSCOBASE & Europe & 510 & 124 & 75 \\
\hline $\begin{array}{l}\text { Fernández Pascual et al. } \\
\text { (2017a) }\end{array}$ & $\begin{array}{l}\text { Cantabrian } \\
\text { Mts }\end{array}$ & 792 & 22 & 14 \\
\hline Liu et al. (2013) & $\begin{array}{l}\text { Qinghai } \\
\text { Tibet }\end{array}$ & 465 & 151 & 42 \\
\hline A. Mondoni, unpublished & Apennines & 32 & 10 & 7 \\
\hline Mondoni et al. $(2009,2012)$ & $\begin{array}{l}\text { European } \\
\text { Alps }\end{array}$ & 506 & 101 & 74 \\
\hline S. Rosbakh, unpublished & Caucasus & 263 & 18 & 9 \\
\hline Rosbakh \& Poschlod (2015) & $\begin{array}{l}\text { European } \\
\text { Alps }\end{array}$ & 971 & 21 & 15 \\
\hline A. Satyanti, unpublished & $\begin{array}{l}\text { Australian } \\
\text { Alps }\end{array}$ & 632 & 91 & 41 \\
\hline Sommerville et al. (2013) & $\begin{array}{l}\text { Australian } \\
\text { Alps }\end{array}$ & 1395 & 13 & 3 \\
\hline Tudela Isanta et al. (2018) & $\begin{array}{l}\text { European } \\
\text { Alps }\end{array}$ & 376 & 47 & 29 \\
\hline $\begin{array}{l}\text { Venn (2007), Venn \& Morgan } \\
\text { (2009) }\end{array}$ & $\begin{array}{l}\text { Australian } \\
\text { Alps }\end{array}$ & 1051 & 15 & 5 \\
\hline
\end{tabular}

morphological dormancy present), physical (germination pre vented by a water impermeable seed coat) or nondormant. We followed the concept by Vleeshouwers et al. (1995) to define dor mancy as an inner seed property (sometimes called 'endodor mancy'), which should be differentiated from the absence of appropriate germination cues in the environment ('ecodormancy'); and the classification system of Baskin \& Baskin (2004) based on previous work by Nikolaeva et al. (1985) who consider morphological and physical dormancy as classes separated from physiological dormancy.

We collected mean seed mass for each species as provided by the Royal Botanic Gardens Kew Seed Information Database (2017) and additional sources (Bu et al., 2007, 2008; Liu et al., 2013). We recorded the embryo to seed surface area ratio for each species. Embryo to seed surface area values were calculated by dividing embryo area by the surface area of the seed, more specifically embryo plus endosperm and perisperm. Measure ments were made using the IMAGEJ software (Schneider et al., 2012) on drawings and photographs of seeds cut in half along the longitudinal axis, retrieved mainly from Martin (1946) and the Royal Botanic Gardens Kew Seed Information Database (2017), supplemented with own photographs (F. Vandelook, unpub lished). For some species that were missing seed mass or embryo values, we calculated genus or family averages. In the case of seed mass, we used species level values for 473 species, and genus aver ages for another 188 species. For embryo mass, we used 21 species level values, 427 genus averages and 213 family averages.
The collected species traits, including information on which taxo nomic rank was used to calculate the values for each species, is available in the data folder of the GitHub repository (see Data Availability statement).

\section{Germination response variables}

We used the final germination proportion (i.e. the number of seeds germinated out of seeds sown) at $8 \mathrm{wk}$ as the main response variable for the germination treatments. The choice of $8 \mathrm{wk}$ was a compromise deadline to unify datasets, as there was a small frac tion of trials that had run for longer times. We further calculated the mean germination time and the germination uncertainty index with the package Germinar (Lozano Isla et al., 2019). Equations for these two germination indices are available in Lozano Isla et al. (2019). Mean germination time is the time that it takes for half of the seed lot to germinate, indicating the germi nation speed in each experimental condition. The germination uncertainty index estimates how scattered germination is through time, giving an idea of whether germination is synchronous (i.e. most seeds germinate around the mean germination time) or asynchronous (i.e. germination events are separated through time during the germination experiment). Lower values in the germi nation uncertainty index indicate higher germination synchrony. The uncertainty index is analogous to the synchrony index and we used it because, unlike the latter, its values are not constrained between 0 and 1 (Lozano Isla et al., 2019). To calculate these indices, we used only records that met two conditions: (1) more than $50 \%$ final germination percentage; and (2) a mean germina tion time under $4 \mathrm{wk}$. Within these limits, we were able to calcu late mean germination time and uncertainty for 293 species. We established this conservative approach to prevent the results being altered by a modification of the seed's dormancy status during the germination incubation (e.g. a fraction of the seed lot is non dormant at the beginning of the incubation and germinates shortly after the start of the experiment; while another fraction is originally dormant, loses dormancy in response to the incubation conditions, and germinates in a second wave). The primary ger mination dataset is available in the data folder of the GitHub repository (see Data Availability statement).

\section{Statistical analyses}

We performed the meta analysis of the germination data by fit ting generalised mixed models with Bayesian estimation (Markov Chain Monte Carlo generalised linear mixed models, MCMCglmms) using the R package MCMCGLmm (Hadfield, 2010). To model final germination proportions, we used bino mial MCMCglmms, while for mean germination time and the germination uncertainty index we used gaussian MCMCglmms. Models had, as fixed effects, the experimental conditions (stratifi cation, $\mathrm{GA}_{3}$, scarification, temperature, alternating temperature and light), plus their interaction with seed mass and embryo : seed, and the strict alpine or generalist character of the species. Random effects included a reconstructed phylogenetic tree for the 661 species, and species identity, seed lot, laboratory 
(i.e. data provider), and alpine region (Table 1). To create the phylogeny, we used the R package V.PHYLOMAKer (Jin \& Qian, 2019) which contains an updated mega tree of the seed plants based on Smith \& Brown (2018). We placed taxa absent from the mega tree at the genus level basal node. The phylogenetic tree is available in the data folder of the GitHub repository (see Data Availability statement). In all models, all variables were scaled so their contribution to the effect sizes could be compared. We used weakly informative priors in all models, with parameter ex panded priors for the random effects. Each model was run for 500000 MCMC steps, with an initial burn in phase of 50000 and a thinning interval of 50 (De Villemereuil \& Nakagawa, 2014), resulting, on average, in 9000 posterior distributions. From the resulting posterior distributions, we calculated mean parameter estimates and 95\% highest posterior density and credi ble intervals (CI). We estimated the significance of model param eters by examining CIs, considering parameters with $\mathrm{CIs}$ overlapping with zero as nonsignificant. To estimate the phyloge netic signal of seed germination over all variables, we used Pagels's lambda ( $\lambda$ ) (Pagel, 1999), estimated simultaneously with the models by calculating the mean of the posterior distribution and the $95 \%$ CI of $\lambda$ as indicated by Villemereuil and Nakagawa (2014). When $\lambda=0$, related taxa are no more similar than expected by chance, while when $\lambda=1$, the trait is evolving follow ing a constant variance random walk or Brownian motion model; intermediate values of $\lambda$ indicate a phylogenetic correlation in trait evolution that does not fully follow a Brownian motion model (Pagel, 1999). Detailed results of the MCMCglmms are available in the results folder of the GitHub repository (see Data Availability statement).

\section{Visualisation of the alpine seed germination spectrum}

To visualise the seed germination spectrum of alpine plants, we employed a factorial analysis of mixed data (FAMD) as imple mented in the package FactoMineR (Le et al., 2008). FAMD ordination combines the properties of PCA and MCA to jointly measure the variation of continuous and categorical variables.
The ordination was performed at the species level, that is calculat ing a series of continuous and categorical traits for each species. We transformed the final germination proportions to create a continuous variable for each germination cue (i.e. stratification, $\mathrm{GA}_{3}$, scarification, temperature, alternating temperatures and light). To do so, for each cue and species, we calculated a weighted average of the cue levels (in the case of temperature, cue levels were the temperature treatments; for the other cues the levels were $0=$ absence and $1=$ presence), weighting by the ger mination proportion at each level. This approach underrepresents the importance of the levels that were not tested for a given species, but can serve as a proxy of the response to the germina tion cues when visualised across the whole dataset; it must be stressed that this stage of the analysis serves only for visualisation and not for hypothesis testing. We also included germination timing traits by calculating single values for the mean germina tion time (the minimum, i.e. the time taken at the most favourable treatment) and the germination uncertainty index (the mean). We conducted the FAMD with the 293 species for which we had mean germination time and germination uncertainty index values. We finally included the continuous variables seed mass and embryo : seed, as well as the categorical variables dor mancy class (physiological, morphophysiological, morphological, physical or nondormant) and distribution (strict alpine vs gener alist species).

\section{Results}

\section{Description of the dataset}

The final dataset used in our meta analysis contained 9799 records (i.e. germination proportions for a given seed lot of a species, recorded in a set of experimental conditions) contributed by 12 research groups, representing 62 seed plant families and 661 species. From these, 291 were categorised as strict alpine species and 370 as generalist. Seed lots were originally sampled in eight alpine regions of the world (Table 1), at middle latitudes of both hemispheres. (a) Seed dormancy classes

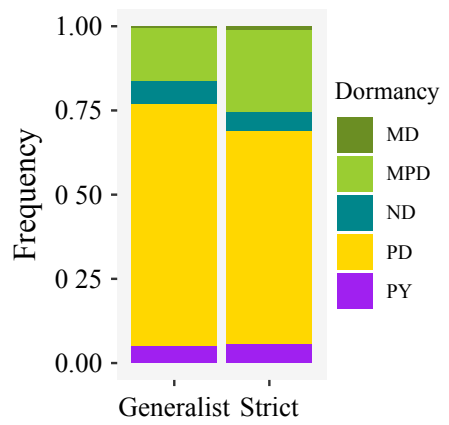

(b) Seed mass

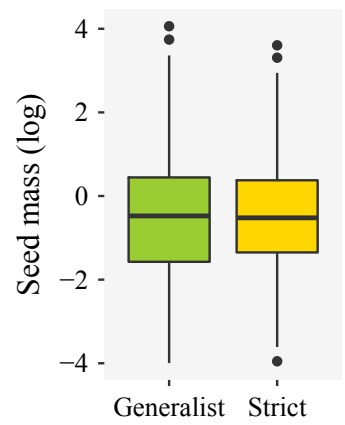

(c) Embryo : seed

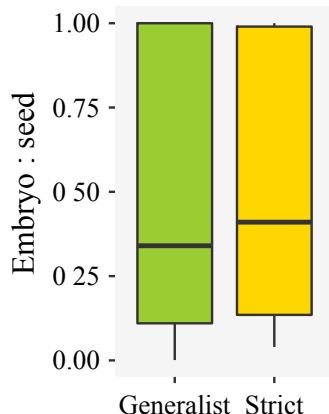

Fig. 1 (a) Seed dormancy classes, (b) seed mass and (c) embryo to seed ratio in the subsets of strict alpine and generalist species analysed in this study. Strict species are mostly restricted to the alpine belt, generalist species can be found in the alpine belt but also below the treeline. Seed dormancy classes are abbreviated as follows: MD (morphological), MPD (morphophysiological), ND (nondormant), PD (physiological), PY (physical). Whiskers in the boxplots $(b, c)$ extend to the most extreme data point which is no more than 1.5 times the length of the box away from the box. 
Most species in the dataset were reported as having dormant seeds (Fig. 1a), but the frequency of the dormancy classes did not differ between generalist and strict alpine species. Among those species with dormant seeds, physiological dormancy was the most common dormancy class, followed by morphophysiological and then physical. Both strict alpine and generalist species had a simi lar range of values for seed mass (Fig. 1b) and embryo : seed ratio (Fig. 1c). The values of seed mass ranged from $0.02 \mathrm{mg}$ (Calceolaria purpurea) to $58 \mathrm{mg}$ (Vicia orobus), with a median value of $0.56 \mathrm{mg}$. Embryo: seed ratio encompassed the full range of potential values, from endospermic species with very small embryos (0.001) to nonendospermic seeds that store nutrients in the cotyledons (1). The median value was 0.34 .

The total number of seeds used in the experiments was 365 808. Germination temperatures (i.e. the weighted average of the day and night temperatures, weighted by the duration of each phase) ranged from 0 to $36^{\circ} \mathrm{C}$, with 7521 records of constant temperatures (i.e. experiments that used the same temperature during all their duration) and 2278 of alternating temperatures (i.e. experiments where different temperatures were applied dur ing the day and the night, in diurnal cycles). Seeds were exposed to light during some part of the diurnal cycle in 8933 records and kept in total darkness in 866 records. The experiments were performed with untreated seeds in 7297 records and, of the rest, the majority (2436) went through cold stratification $\left(<5^{\circ} \mathrm{C}\right.$, in darkness). Scarification (i.e. an abrasion of the seed coat to allow water imbibition) was performed in 119 records, and $\mathrm{GA}_{3}$ (a plant hormone that promotes embryo growth and stimulates ger mination) in 651 records.

\section{(a) Effect on final germination proportions}
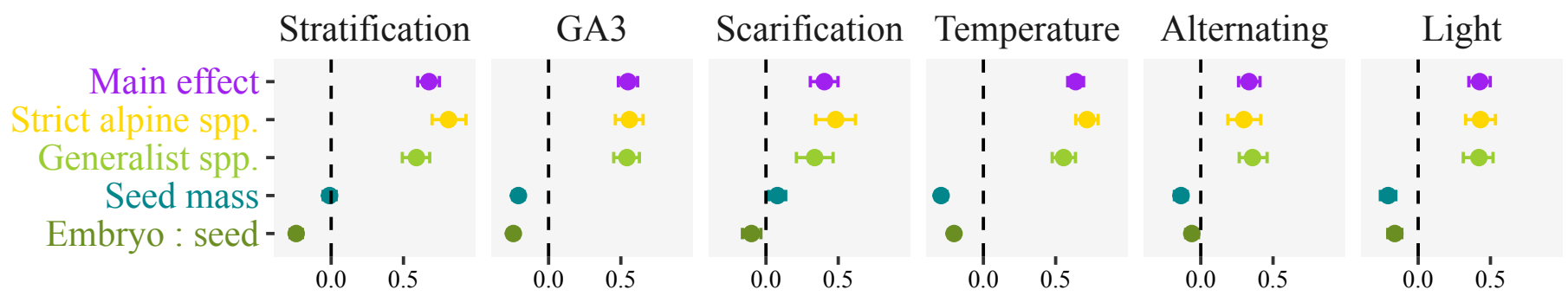

Effect size

\section{(b) Effect on mean germination time}

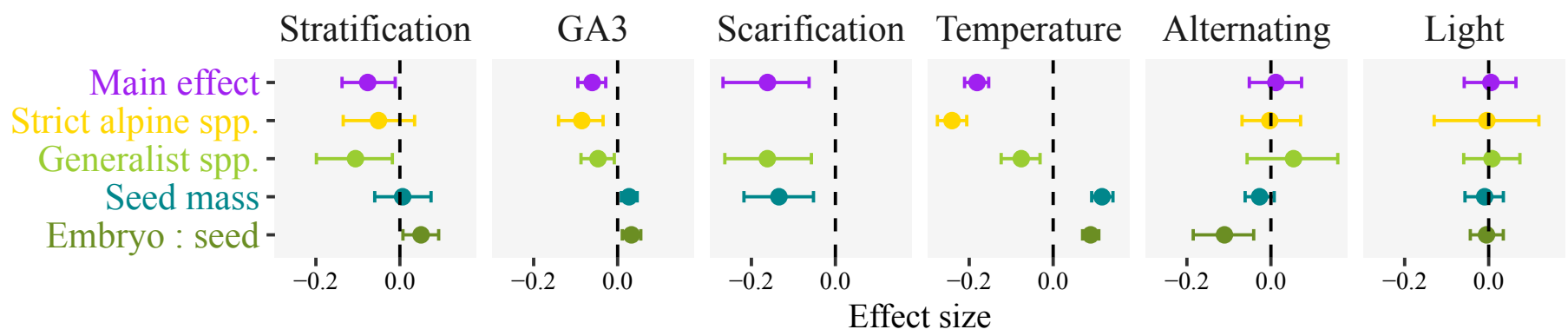

\section{(c) Effect on germination uncertainty}

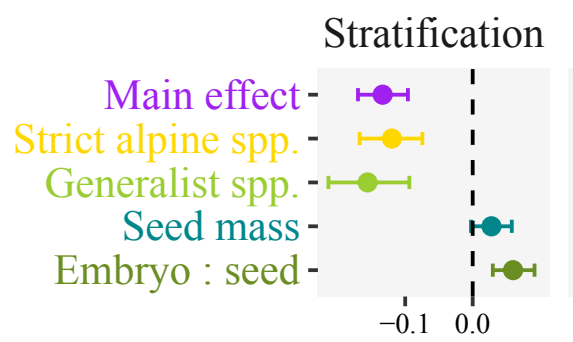

\section{GA3}

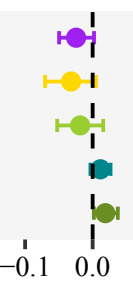

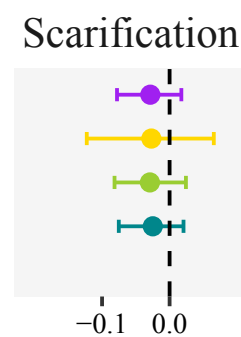

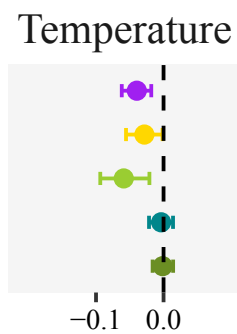

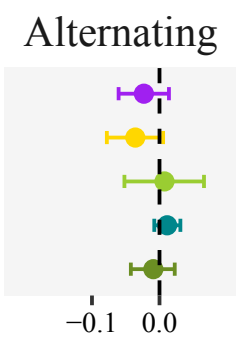

\section{Effect size}

Fig. 2 Effect of the germination environment on (a) final germination proportions, (b) mean germination time and (c) germination uncertainty index; according to the MCMC meta analysis of primary data. Dots indicate the posterior mean of the effect size, and whiskers its $95 \%$ credible interval. The line of zero effect is shown. When the credible intervals overlap with the zero effect line, the effect is not significant. Some effects that overlapped with zero (i.e. had no effect) and whose credible intervals were excessively wide are not shown for clarity's sake. The figure shows first the main effect, then the effects for the strict alpine and generalist groups, and then the interaction with seed mass and embryo : seed. A negative interaction (e.g. seed mass and light, in the case of the germination proportion) indicates that, as the interacting factor increases (e.g. seed mass) the response to the germination cue (e.g. light) decreases, in comparison with the main effect. GA3, gibberellic acid. 


\section{Dormancy-alleviating treatments}

In general, stratification significantly increased the final germination proportion (Fig. 2a), as shown by a credible interval not overlap ping zero. This positive effect occurred in both generalist and strict alpine species, although the effect size was larger in the strict alpine group. Stratification slightly reduced the mean germination time (Fig. 2b), which was evident in the generalist species, but not in the strict alpine species. Further, stratification reduced the germination uncertainty index as a general response (Fig. 2c), and slightly more so in generalist species. Seed mass did not interact with stratifica tion, but species with larger embryos had a smaller response to strat ification in their final germination proportion and reduced less markedly their mean germination time and germination uncer tainty index. $\mathrm{GA}_{3}$ had similar effects to stratification, with the main difference being that seed mass affected the response to $\mathrm{GA}_{3}$, whereas it did not interact with the response to stratification.

Scarification promoted the germination proportion (Fig. 2a) and reduced the mean germination time (Fig. 2b), but it did not affect the germination uncertainty index (Fig. 2c). Strict alpine species were slightly more responsive to scarification than general ist species. Heavier seeds were more responsive to scarification, while seeds with larger embryos responded less.

\section{Germination temperature}

Temperature had a positive significant effect on the final germina tion proportion (Fig. 2a), indicating a preference for warmer tem peratures. Warmer temperatures also significantly decreased mean germination time (Fig. 2b) and the germination uncertainty index (Fig. 2c). The effect of warmer temperatures was slightly higher in strict alpine than in generalist species, although the CI of the two groups of species do overlap. Seed mass and embryo : seed had a negative interaction with temperature, reducing the response to temperature. In other words, heavier and less endospermic seeds had a smaller increase in germination proportion and a smaller decrease in mean germination time when germinating in warmer temperatures. The germination uncertainty index did not show an interaction with seed mass or embryo : seed.

\section{Alternating temperatures}

Alternating temperatures had a positive effect on the final germi nation proportion (Fig. 2a), but not on the mean germination time (Fig. 2b) or the germination uncertainty index (Fig. 2c). The positive effect on the germination proportion was slightly higher in the generalist species. As in the case of the mean germi nation temperature, higher seed mass and embryo : seed values reduced the positive effect of alternating temperatures on the final germination proportion. Alternating temperatures resulted in faster germination (reduced the mean germination time) for seeds with low values of embryo : seed.

\section{Light}

Light increased the final germination proportion (Fig. 2a), with no differences between strict alpine and generalist species. It did not affect the mean germination time (Fig. 2b), but it did result in more variable germination (increased the germination uncer tainty index) of generalist species (Fig. 2c). Heavier and less endospermic seeds responded less to light.

\section{Random effects and phylogenetic signal}

Random factors had a significant effect in the MCMCglmm models (Fig. 3). The final germination proportion and the mean germination time were affected more strongly, on average, by the seed lot and the species identity, suggesting that these traits are subject to intra and interspecific variability, respectively. Alpine region and laboratory had a lower average effect and more vari ability as shown by their CI. The germination uncertainty index showed the opposite pattern, with a stronger effect of laboratory and alpine region. The phylogenetic signal in the response to all germination parameters (Fig. 4) was significantly positive for the final germination proportion and the mean germination time. For the germination uncertainty index, phylogenetic signal over lapped with zero, indicating a weak effect of phylogeny. The results for the germination uncertainty index indicate that it might have been more sensitive to the frequency of germination scoring, which was different in different laboratories. Detailed values of phylogenetic signal for all model interactions are avail able in the results folder of the GitHub repository (see Data Availability statement).

\section{FAMD ordination}

The first FAMD axis explained $17 \%$ of the variation (Fig. 5). The quantitative variables with the largest contribution to this first axis were germination temperature, germination uncertainty, $\mathrm{GA}_{3}$ and alternating temperatures. Among the qualitative factors, the strict alpine/generalist categories contributed to axis 1 . In summary, the horizontal axis separated (i, left) generalist species with a positive response to alternating temperatures and more germination uncertainty from (ii, right) strict alpine species with a preference for warmer temperatures and a positive response to $\mathrm{GA}_{3}$. Axis 2 explained $12 \%$ of the variability. The main con tributing variables were embryo : seed, mean germination time, seed mass and scarification; and the main categorical factors were physical dormancy and morphophysiological dormancy. This axis separated (iii, bottom) morphophysiologically dormant species with longer mean time to germination from (iv, top) physically dormant species that responded to scarification and had heavier, less endospermic seeds.

\section{Discussion}

Our meta analysis of primary germination data shows that alpine seeds tend to germinate when, after weeks of exposure to condi tions that mimic winter, they experience mid summer tempera tures. The germination ecology of strict alpine species is characterised by: (1) physiological seed dormancy; (2) a strong need for cold stratification or $\mathrm{GA}_{3}$ to alleviate dormancy; (3) warm cued germination; (4) a positive response to alternating 
(a) Effect on final germination proportions
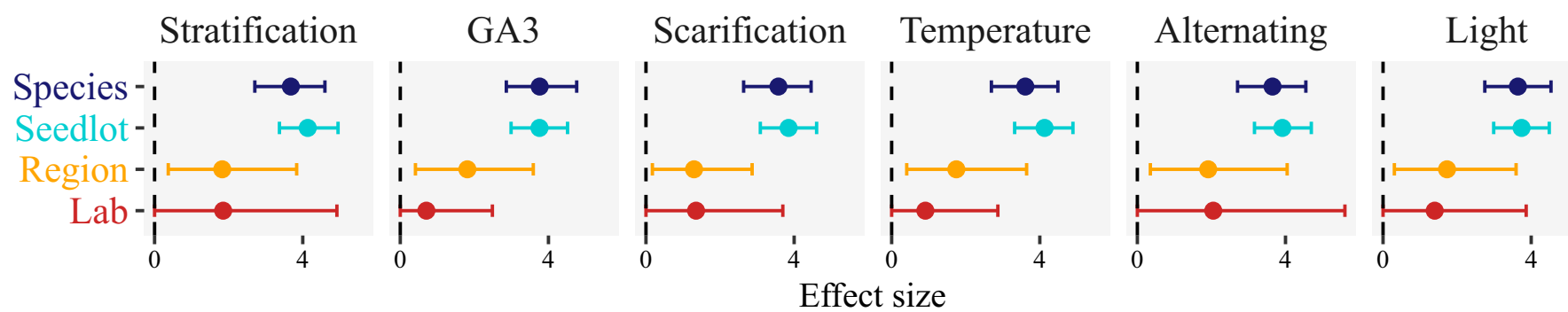

(b) Effect on mean germination time
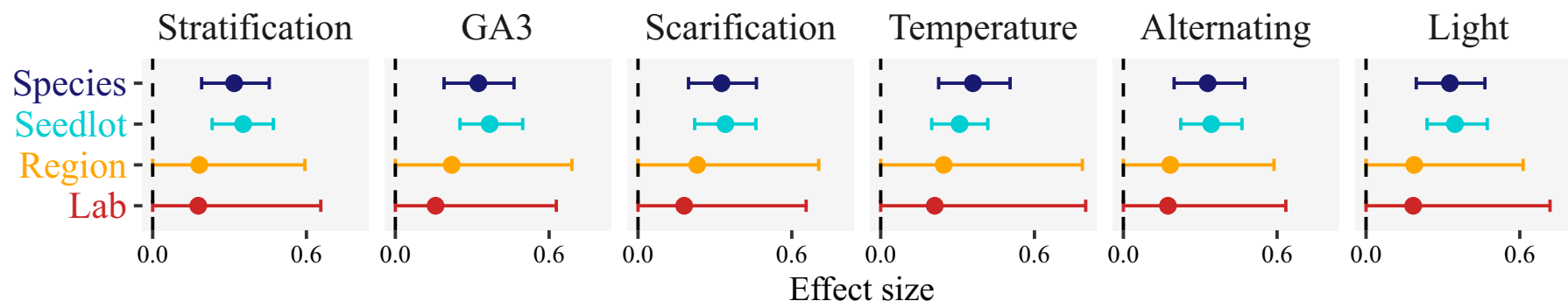

(c) Effect on germination uncertainty

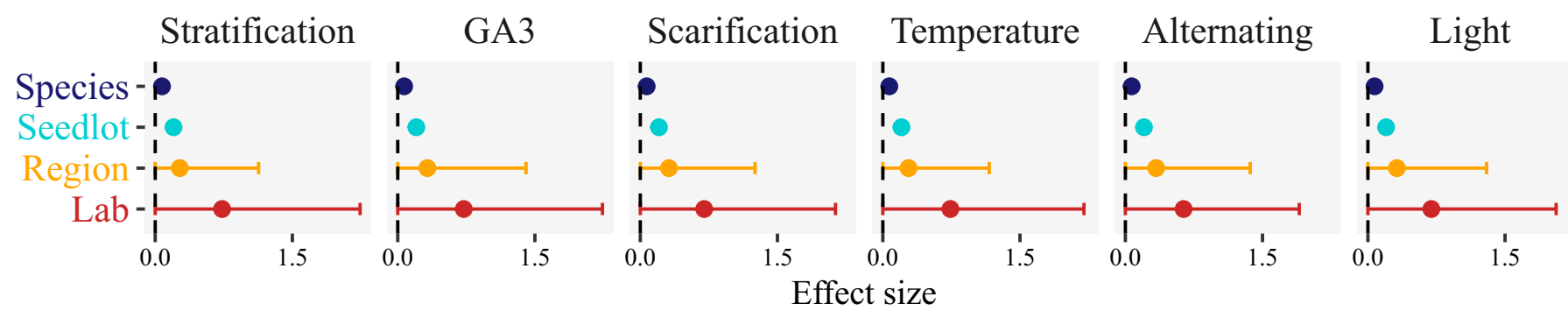

Fig. 3 Effect of the random factors on (a) final germination proportions, (b) mean germination time and (c) germination uncertainty index; according to the MCMC meta analysis of primary data. Dots indicate the posterior mean of the effect size, and whiskers its $95 \%$ credible interval. The line of zero effect is shown. GA3, gibberellic acid.

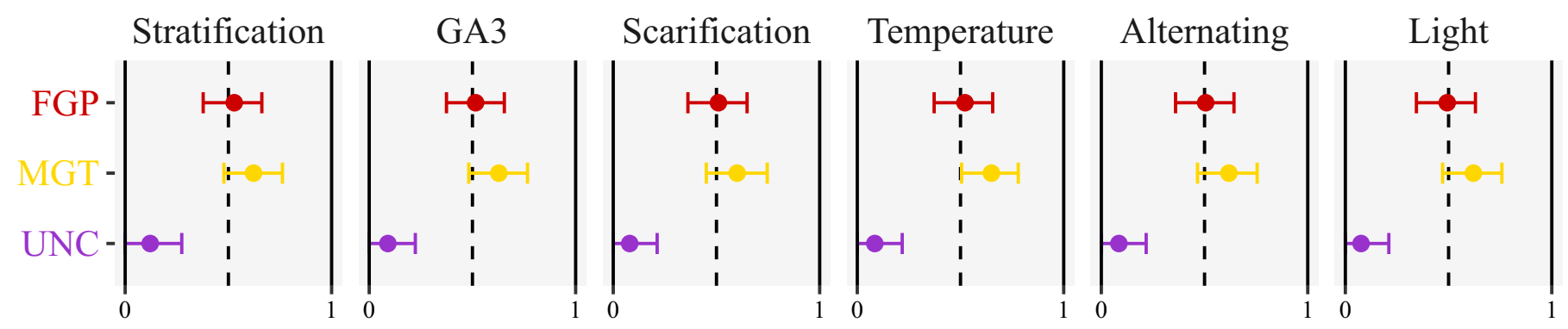

Pagel's lambda

Fig. 4 Phylogenetic signal in the response to the germination environment. Dots indicate the posterior mean of lambda, and whiskers its $95 \%$ credible interval. When lambda $\quad 0$, related taxa are no more similar than expected by chance; when lambda $\quad 1$, the trait is evolving following a constant variance random walk or Brownian motion model. GA3, gibberellic acid; FGP, final germination proportion; MGT, mean germination time; UNC, germination uncertainty index.

temperatures, although not so prominent as in generalist species; (5) a positive response to light; (6) slow and relatively syn chronous germination; and (7) an interplay with seed and embryo size, with smaller and more endospermic seeds being more responsive to stratification, warmth, alternating tempera tures and light. Here we discuss the ecological significance of 
Fig. 5 Factorial analysis of mixed data (FAMD) ordination of the alpine seed germination spectrum. Each square is a species. Labels indicate the contribution of the variables to the axes. $(a, b)$ Quantitative traits. (c, d) Qualitative traits. GA3, gibberellic acid; MGT, mean germination time; UNC, germination uncertainty index. Seed dormancy classes are abbreviated as follows: MD (morphological), MPD (morphophysiological), ND (nondormant), PD (physiological), PY (physical). Strict species are mostly restricted to the alpine belt, generalist species can be found in the alpine belt but also below the treeline.

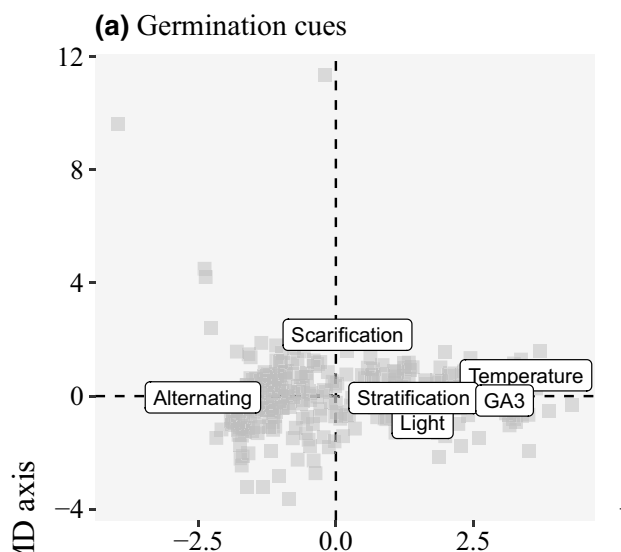

(c) Dormancy class
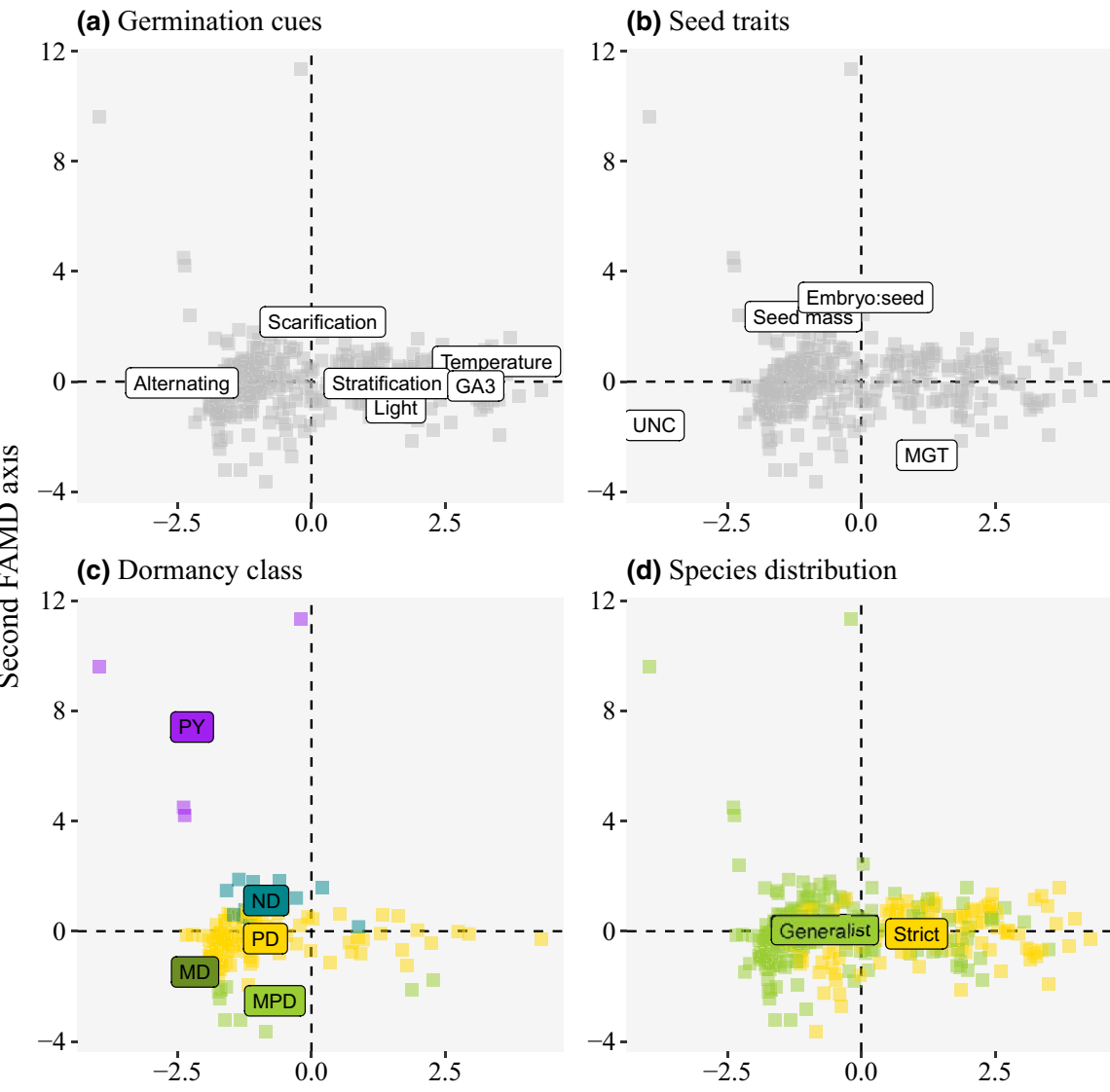

(d) Species distribution

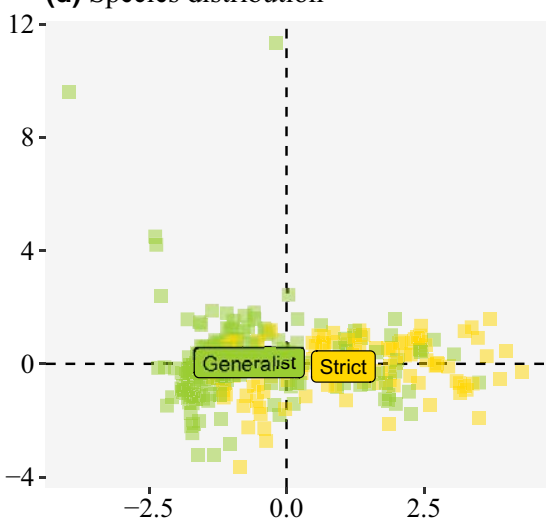

First FAMD axis these responses and how they define the seed germination spec trum of alpine plants.

\section{Seed dormancy}

Our dataset showed that seed dormancy is frequent across alpine species and plays an important role in postponing plant recruit ment to favourable times. The frequency of dormancy classes dis played by strict alpine and generalist species was similar, suggesting that this is a general trait of cold adapted mountain species. Seeds with the two most frequent dormancy classes, that is physiological and morphophysiological, require a stratification period during which certain conditions (e.g. cold and wet, although other combinations are possible) are met over a period of months (Baskin \& Baskin, 2014; Rosbakh et al., 2020a). Indeed, our results show that cold stratification consistently pro motes germination, while the phytohormone gibberellic acid $\left(\mathrm{GA}_{3}\right)$ works as a substitute of cold stratification to overcome physiological dormancy. Additionally, we found some species with physical dormancy. This dormancy type can be broken by mechanical scarification via freezing-thawing cycles in spring or extreme temperature fluctuations during summer, but it is also capable of responding to seasonal cycles of temperature and humidity (Van Assche et al., 2003).

Together, these results confirm that overwintering is essential for promoting seed germination in alpine species, concurring with previous local studies (Cavieres \& Arroyo, 2000; Schütz, 2002; Giménez Benavides et al., 2005; Shimono \& Kudo, 2005; Sommerville et al., 2013; García Fernández et al., 2015; Hoyle et al., 2015; Fernández Pascual et al., 2017a; Cavieres \& Sierra Almeida, 2018). As global climate change is causing major changes in snow cover duration (Beniston, 2012; Gobiet et al., 2014), it could disrupt natural cold stratification cycles in alpine environments, compromising population viability and indirectly favouring species with no stratification requirement (Sommerville et al., 2013). This risk will be partly alleviated by the plasticity of physiological seed dormancy in response to the seed maturation temperature (Fernández Pascual et al., 2013; Carta et al., 2016b). 'Seed memory' via maternal effects facilitates acclimatisation to changing environments, and can reduce the stratification require ments of seeds produced in a warmer climate (Fernández Pascual et al., 2019).

\section{Thermal regulation of germination}

We found a general increase in seed germination with higher incubation temperatures. This effect was more pronounced in strict alpine compared with generalist species, confirming previ ous local studies (Walder \& Erschbamer, 2015; Fernández Pas cual et al., 2017a). It was also more pronounced in small seeded and endospermic species. Small seeded species have a lower pro portion of seedling survival under drought (Leishman \& 
Westoby, 1994), but may require warmer germination tempera tures than large seeded species, especially in seasonal climates (Arène et al., 2017). Considering that risk reduction is an impor tant selective pressure for the evolution of germination traits (Venable \& Brown, 1988), a plausible explanation for these pat terns is that alpine plants received selection pressure from damag ing spring frosts and evolved a frost avoidance mechanism by germinating at high temperatures (Taschler \& Neuner, 2004; Marcante et al., 2012; Rosbakh et al., 2020b). Moreover, strict alpine species may be less subjected to drought damage during establishment compared with generalist species: as elevation increases, plants face less drought risk because precipitation increases (except in Mediterranean and semiarid mountains), but at the same time there is a higher probability of early or late sea son frosts (Körner, 2003; Schrier et al., 2007; Beniston, 2016). Together, these results indicate that germination patterns in alpine species are driven by an interplay of seed size and germina tion temperature to escape either frost or drought stress: small seeds are being selected for fast germination at warm tempera tures, in order to escape unfavourable early spring frost; while large seeds are being selected for slower germination under cooler conditions, which should maximise emergence during snowmelt (when water availability is highest) giving seedlings adequate time to develop a root system to cope with desiccation risks in sum mer. Supporting this view, seedlings of alpine pioneer species have a low frost resistance (Marcante et al., 2012), yet can tolerate heat up to $40-50^{\circ} \mathrm{C}$ (Marcante et al., 2014).

In our analysis, increasing temperatures also decreased germi nation uncertainty, showing that germination synchrony is a plas tic trait driven by temperature. While asynchronous germination is thought to be a form of adaptation to unpredictable environ ments (Wagner \& Simons, 2009; Simons, 2011), our results indicate that asynchronous germination occurs when tempera tures are relatively cool, likely as a bet hedging strategy against the risk of early spring frost. Conversely, a fast and synchronised germination at warm conditions (i.e. in late spring) may be another important strategy that increases alpine seedling survival by avoiding drier conditions in summer. The extreme germina tion uncertainty syndrome, that is staggering germination so that emergence occurs both before and after winter, is known in alpine species (Körner, 2003; Hoyle et al., 2015; Satyanti et al., 2019). If autumn seedlings grow faster than spring seedlings (Satyanti et al., 2019), this will probably have cascading effects on individual fitness along the life of the plant (Donohue et al., 2005, 2010)

\section{Alternating temperatures and light}

We also found a positive germination response to alternating temperatures and light, conditions that mimic the environment in the upper soil and certain microsites during the snow free sea son (Billings \& Mooney, 1968; Körner, 2003; Mondoni et al., 2012). Alternating temperatures had a slightly lower effect on strict alpine species, compared with generalist species, but still had some effect. This partly contradicts the findings of Liu et al. (2013), who found no response to temperature fluctuations for species distributed only at high elevations of the Qinghai Tibet Plateau. Liu and co workers argued that, in that area, high tem perature fluctuations may occur throughout the year, and there fore fluctuating temperature alone may not be a reliable indicator of suitable conditions for seedling establishment and growth (Liu et al., 2013). When analysed here at the global level, alternating temperatures generally increased germination of alpine seeds, which corresponds well with the fact that most alpine regions have a strong day/night climatic variation during the growing sea son. It is also not surprising that we detected a negative interac tion between seed mass and the germination response to light and alternating temperature regimes, as large seeds can afford to germinate at greater depths (where they are more protected from the alpine environment) and still reach the soil surface (Bond et al., 1999; Pons, 2000).

\section{The alpine seed germination spectrum}

Using the whole set of traits compiled in this study we can visu alise the seed germination spectrum of alpine plants. At one end of the spectrum, strict alpine species tend to germinate slowly and synchronously, require warm temperatures and light to ger minate, and need stratification or $\mathrm{GA}_{3}$ to alleviate physiological dormancy. At the other end, generalist species tend to germinate fast, show a bet hedging strategy (i.e. high germination uncer tainty) and germination traits that suggested fast germination after specific cues (e.g. scarification or alternating temperatures). The dormancy classes without a physiological component (non dormant, physical, and morphological) appear to be associated with generalist species. This gradient of regenerative strategies mirrors prominent gradients of fast or slow population dynamics (Silvertown et al., 1992; Nobis \& Schweingruber, 2013), fast or slow developing leaf traits (Wright et al., 2004), or large sets of plant ecological features (Grime, 1977). 'Fast' regeneration can be understood as a plastic and opportunistic strategy to cope with frequently disturbed habitats such as avalanche ways, steep erod ing slopes, regressing glaciers, and riverbeds (Pierce et al., 2007; Gentili et al., 2013). The 'slow' regeneration of strict alpine species, conversely, seems to be a more specialised syndrome and might be the result of convergent evolution acting on those species that are truly restricted to the alpine vegetation belt.

A general assumption of seed trait ecology is that seed mass and embryo : seed ratios are relatively conserved across related species (Moles et al., 2005; Vandelook et al., 2012). In our alpine dataset, both traits showed no differences between strict alpine and generalist species. This was in line with the ambiguity of rela tionships between seed mass and elevation that have been found for alpine species, including examples of negative (Wang et al., 2014), positive (Pluess et al., 2005) or absent (Vandelook et al., 2012; Bauk et al., 2015) correlations. The similarity in embryo : seed ratio between generalist and strict alpine species also confirmed the lack of correlation between embryo : seed ratio and elevation found in the Apiaceae (Vandelook et al., 2012). By contrast with the supposed phylogenetic conservatism of these morphological traits, physiological germination responses are understood to be more plastic traits that can quickly respond to 
new situations (Fernández Pascual et al., 2019). While phyloge netic signal in seed germination is generally found, especially in highly selective environments (Carta et al., 2016a; Arène et al., 2017; Fernández Pascual et al., 2017b), germination patterns can also be shared between phylogenetically distant species (Vande look et al., 2019) and have low or absent phylogenetic signal (Rosbakh \& Poschlod, 2015; Fang et al., 2017; Fernández Pas cual et al., 2017a). The phylogenetic signal in germination responses that we found here indicates that evolutionary history cannot be neglected when studying seed germination patterns. Furthermore, we detected that seed embryo size influences ger mination responses to environmental cues, with smaller and more endospermic seeds being more responsive to warmth, light and alternating temperatures. Previous studies have shown that nonendospermic seeds are smaller and are likely to be nondor mant at the time of dispersal and thus germinate more quickly than alpine endospermic seeds (Sommerville et al., 2013; Hoyle et al., 2015; Satyanti et al., 2019). Together, these results indicate that seed morphology and physiology are connected and may be subjected to co adaptation. This connection, intertwined with their shared phylogenetic history, may constrict the potential variability of the seed ecological spectrum.

\section{Future directions}

Our first global assessment of the seed germination spectrum in relation to seed morphology supports the existence of trade offs between sets of regenerative traits (Saatkamp et al., 2019), such as the relationship we found between seed/embryo size, germination speed and germination responses to temperature and light. Future studies will need to consider, as we did, evolutionary his tory and seed morphology as intrinsic constraints of the seed eco logical spectrum; while the seed germination spectrum we described here needs to be explored at the community level (Jiménez Alfaro et al., 2016).

This study also highlights the general lack of seed germination studies on tropical alpine species. Although there is an increasing interest in the ecology of plants from tropical alpine regions, we could not find seed germination data to include in our meta anal ysis. Compared with temperate alpine ecosystems, tropical alpine environments are relatively aseasonal and most plants have been reported as flowering throughout the year (Gehrke, 2018). Rather than being exposed to snow in winter and high tempera tures in summer, tropical alpine plants face a year round stress from night time frost (Körner, 2003). These different selective pressures suggest that the cold adapted germination syndrome of temperate alpine seeds may not be prevalent in the tropical alpine flora. That means that our study is valid for temperate alpine regions, where alpine habitats mainly occur (Testolin et al., 2020), but not necessarily for tropical alpine systems. We thus recommend future research to focus on the seed ecology of high mountain tropical areas.

Another aspect that calls for future efforts is a finer study of germination cues. To produce this meta analysis, we had to assume some simplifications in order to merge disparate datasets: we considered coarse cues that are routinely recorded in germina tion tests, like the presence/absence of light, alternating tempera tures or cold stratification. New research should aim to decompose these binary cues into finer quantitative variables which provide a more precise environmental signalling, such as the red : far red ratio (Jankowska Blaszczuk \& Daws, 2007), the length of the photoperiod (Black \& Wareing, 1954), the ampli tude of the diurnal thermal oscillations (Fernández Pascual et al., 2015) or the length and temperature of cold stratification (Pritchard et al., 1996). In addition, new field research is neces sary to assess germination phenology in response to temperature and water availability on the upper soil layer.

\section{Conclusions}

This study demonstrates how alpine plants from different regions of the world respond similarly to germination cues that support successful regeneration: cold stratification, warm and alternating temperatures and light. These cues, particularly cold stratification and warm temperatures, are generally associated with cold adapted herbaceous species in a broad sense (Fenner \& Thomp son, 2005; Baskin \& Baskin, 2014; Rosbakh \& Poschlod, 2015). Nonetheless, our results show that the response to stratification and temperature is more prominent in strict alpine species when comparing them with generalist plants that can grow opportunis tically in the alpine belt. This suggests an evolutionary conver gence of germination patterns in those species truly adapted to alpine ecosystems. We can conclude that, while alpine plants do not show a unique germination syndrome, they do show a more extreme or specialised version of the cold adapted temperate ger mination syndrome.

\section{Acknowledgements}

EFP received financial support from the Government of Asturias and the FP7 - Marie Curie - COFUND programme of the European Commission (Grant 'Clarín' ACB17 19). BJ A and EFP were funded by the Spanish Research Agency (PID2019 108636GA/AEI/10.13039/501100011033). EM was supported by the Future Leaders Fellowship - Diversity and Livelihoods, of the Royal Botanic Gardens, Kew. Authors thank Amelia Martyn Yenson and Catherine A. Offord for germination and dormancy data for 19 Australian alpine species. This research was supported by NGSeeds, the Next Generation Seed Ecology, Evolution and Data Science virtual working group.

\section{Author contributions}

BJ A conceived the original idea. EFP, AC, AM, LC, SR, SV, ASatyanti, LG, VFB, FV, HB, KS, PP, KL and AN contributed data. EFP assembled and managed the database. AC and EFP analysed data. EFP led manuscript writing, with contributions from BJ A, AC, AM, LC, SR, SV, ASatyanti, LG, VFB, FV, EM and ASaatkamp. All authors revised the manuscript and approved the final version. 


\section{ORCID}

Haiyan Bu iD https://orcid.org/0000 00019944 475X

Angelino Carta (D) https://orcid.org/0000 00018437 818X

Lohengrin A. Cavieres (iD https://orcid.org/0000 00019122

3020

Eduardo Fernández Pascual (iD https://orcid.org/0000 0002 47439577

Lydia Guja iD https://orcid.org/0000 00015945 438X

Borja Jiménez Alfaro (iD https://orcid.org/0000 00016601

9597

Kun Liu (D https://orcid.org/0000 00019127 053X

Efisio Mattana iD https://orcid.org/0000 000162354603

Andrea Mondoni iD https://orcid.org/0000 000246056304

Adrienne Nicotra (D https://orcid.org/0000 $00016578369 \mathrm{X}$

Peter Poschlod iD https://orcid.org/0000 000344737656

Sergey Rosbakh (iD https://orcid.org/0000 000245996943

Arne Saatkamp iD https://orcid.org/0000 000156380143

Annisa Satyanti (iD https://orcid.org/0000 000339224346

Karen Sommerville iD https://orcid.org/0000 000298436616

Filip Vandelook iD https://orcid.org/0000 000345915557

Susanna Venn (iD https://orcid.org/0000 000274330120

\section{Data availability}

The original data, $\mathrm{R}$ code for the analysis and creation of the manuscript can be accessed at the GitHub repository https:// github.com/efernandezpascual/alpineseeds. A version of record of the repository can be found at https://doi.org/10.5281/zenodo. 4270344

\section{References}

Amen RD. 1966. The extent and role of seed dormancy in alpine plants. Quarterly Review of Biology 41: 271281.

Angevine MW, Chabot BF. 1979. Seed germination syndromes in higher plants. In: Solbrig OT, Jain S, Johnson GB, Raven PH, eds. Topics in plant population biology. New York, NY, USA: Columbia University Press, 188206.

Arène F, Affre L, Doxa A, Saatkamp A. 2017. Temperature but not moisture response of germination shows phylogenetic constraints while both interact with seed mass and lifespan. Seed Science Research 27: 110120.

Arroyo MTK, Cavieres LA, Castor C, Humana AM. 1999. Persistent soil seed bank and standing vegetation at a high alpine site in the central Chilean Andes. Oecologia 119: 126132.

Arslan H, Kirmizi S, Guleryuz G, Sakar F. 2011. Germination requirements of Androsace villosa L. (Primulaceae). Acta Biologica Cracoviensia Series Botanica 53: 3236.

Baskin CC, Baskin JM. 2014. Seeds. Ecology, Biogeography and Evolution of Dormancy and Germination, $2^{\text {nd }}$ edn. San Diego, CA, USA: Academic Press.

Baskin JM, Baskin CC. 2004. A classification system for seed dormancy. Seed Science Research 14: 116.

Bauk K, Pérez-Sánchez R, Zeballos SR, Las Penas ML, Flores J, Gurvich DE. 2015. Are seed mass and seedling size and shape related to altitude? Evidence in Gymnocalycium monvillei (Cactaceae). Botany-Botanique 93: 529533.

Beniston M. 2012. Is snow in the Alps receding or disappearing? WIREs Climate Change 3: 349358.

Beniston M. 2016. Environmental change in mountains and uplands. London, UK: Routledge.

Bewley JD, Bradford K, Hilhorst H, Nonogaki H. 2013. Seeds: physiology of development, germination and dormancy, $3^{\text {rd }} e d n$. Berlin/Heidelberg, Germany: Springer.
Billings WD, Mooney HA. 1968. The ecology of arctic and alpine plants. Biological Reviews 43: 481529.

Black M, Wareing P. 1954. Photoperiodic control of germination in seed of birch (Betula pubescens Ehrh.). Nature 174: 705706.

Bliss LC. 1958. Seed germination in arctic and alpine species. Arctic 11: 180 188.

Bond WJ, Honig M, Maze KE. 1999. Seed size and seedling emergence: an allometric relationship and some ecological implications. Oecologia 120: 132 136.

Brach AR, Song H. 2006. eFloras: new directions for online floras exemplified by the Flora of China project. Taxon 55: 188192.

Bu H, Chen X, Xu X, Liu K, Jia P, Du G. 2007. Seed mass and germination in an alpine meadow on the eastern Tsinghai-Tibet plateau. Plant Ecology 191: 127149

Bu H, Du G, Chen X, Xu X, Liu K, Wen S. 2008. Community-wide germination strategies in an alpine meadow on the eastern Qinghai-Tibet plateau: phylogenetic and life-history correlates. Plant Ecology 195: 8798.

Carta A, Hanson S, Muller JV. 2016a. Plant regeneration from seeds responds to phylogenetic relatedness and local adaptation in Mediterranean Romulea (Iridaceae) species. Ecology and Evolution 6: 41664178.

Carta A, Probert R, Puglia G, Peruzzi L, Bedini G. 2016b. Local climate explains degree of seed dormancy in Hypericum elodes L. (Hypericaceae). Plant Biology 18: 7682.

Carta A, Skourti E, Mattana E, Vandelook F, Thanos CA. 2017. Photoinhibition of seed germination: occurrence, ecology and phylogeny. Seed Science Research 27: 131153

Castroviejo S. 1987. Flora iberica. Madrid, Spain: Real Jardín Botánico, CSIC.

Cavieres LA, Arroyo MTK. 2000. Seed germination response to cold stratification period and thermal regime in Phacelia secunda (Hydrophyllaceae). Plant Ecology 149: 18.

Cavieres LA, Arroyo MTK. 2001. Persistent soil seed banks in Phacelia secunda (Hydrophyllaceae): experimental detection of variation along an altitudinal gradient in the Andes of central Chile (33 S). Journal of Ecology 89: 3139.

Cavieres LA, Sierra-Almeida A. 2018. Assessing the importance of coldstratification for seed germination in alpine plant species of the High-Andes of central Chile. Perspectives in Plant Ecology, Evolution and Systematics 30: 125 131.

Cayuela L, Stein A, Oksanen J. 2019. Taxonstand: taxonomic standardization of plant species names. R package v.2.2. [WWW document] URL https://CRAN. R-project.org/package Taxonstand.

Chambers JC, MacMahon JA, Brown RW. 1990. Alpine seedling establishment: the influence of disturbance type. Ecology 71: 13231341.

De Villemereuil P, Nakagawa S. 2014. General quantitative genetic methods for comparative biology. In: Garamszegi LZ, ed. Modern phylogenetic comparative methods and their application in evolutionary biology. Berlin/Heidelberg, Germany: Springer, 287303.

Densmore R. 1997. Effect of day length on germination of seeds collected in Alaska. American Journal of Botany 84: 274.

Donohue K, Dorn L, Griffith C, Kim E, Aguilera A, Polisetty CR, Schmitt J. 2005. Niche construction through germination cueing: life-history responses to timing of germination in Arabidopsis thaliana. Evolution 59: 771785.

Donohue K, Rubio de Casas R, Burghardt L, Kovach K, Willis CG. 2010. Germination, postgermination adaptation, and species ecological ranges. Annual Review of Ecology, Evolution, and Systematics 41: 293319.

Fang X-W, Zhang J-J, Xu D-H, Pang J, Gao T-P, Zhang C-H, Li F-M, Turner NC. 2017. Seed germination of Caragana species from different regions is strongly driven by environmental cues and not phylogenetic signals. Scientific Reports 7: 11248 .

Fenner M, Thompson K. 2005. The ecology of seeds. Cambridge, UK: Cambridge University Press.

Fernández-Pascual E, Jiménez-Alfaro B, Bueno Á. 2017a. Comparative seed germination traits in alpine and subalpine grasslands: higher elevations are associated with warmer germination temperatures. Plant Biology 19: 3240.

Fernández-Pascual E, Jiménez-Alfaro B, Caujapé-Castells J, Jaén-Molina R, Díaz TE. 2013. A local dormancy cline is related to the seed maturation environment, population genetic composition and climate. Annals of Botany 112: 937945. 
Fernández-Pascual E, Mattana E, Pritchard HW. 2019. Seeds of future past: climate change and the thermal memory of plant reproductive traits. Biological Reviews 94: 439456.

Fernández-Pascual E, Pérez-Arcoiza A, Prieto JA, Díaz TE. 2017b. Environmental filtering drives the shape and breadth of the seed germination niche in coastal plant communities. Annals of Botany 119: 11691177.

Fernández-Pascual E, Seal CE, Pritchard HW. 2015. Simulating the germination response to diurnally alternating temperatures under climate change scenarios: comparative studies on Carex diandra seeds. Annals of Botany 115: 201209.

Forbis TA. 2003. Seedling demography in an alpine ecosystem. American Journal of Botany 90: 11971206.

Garamszegi LZ. 2014. Modern phylogenetic comparative methods and their application in evolutionary biology. Berlin/Heidelberg, Germany: Springer.

García-Fernández A, Escudero A, Lara-Romero C, Iriondo JM. 2015. Effects of the duration of cold stratification on early life stages of the Mediterranean alpine plant Silene ciliata. Plant Biology 17: 344350.

Gehrke B. 2018. Staying cool: preadaptation to temperate climates required for colonising tropical alpine-like environments. PhytoKeys 96: 111125.

Gentili R, Armiraglio S, Sgorbati S, Baroni C. 2013. Geomorphological disturbance affects ecological driving forces and plant turnover along an altitudinal stress gradient on alpine slopes. Plant Ecology 214: 571586.

Giménez-Benavides L, Escudero A, Pérez-García F. 2005. Seed germination of high mountain Mediterranean species: altitudinal, interpopulation and interannual variability. Ecological Research 20: 433444.

Gobiet A, Kotlarski S, Beniston M, Heinrich G, Rajczak J, Stoffel M. 2014. 21st century climate change in the European Alps a review. Science of the Total Environment 493: 11381151.

Grime JP. 1977. Evidence for the existence of three primary strategies in plants and its relevance to ecological and evolutionary theory. American Naturalist 111: 11691194.

Hadfield JD. 2010. MCMC methods for multi-response generalized linear mixed models: the MCMCglmm R package. Journal of Statistical Software 33: 122.

Hegi G. 1906. Illustrierte Flora von Mitteleuropa, mit besonderer Berucksichtigung von Deutschland, Osterreich und der Schweiz, $1^{\text {st }}$ edn 1906 1931, $2^{\text {nd }}$ edn 1936 1979, $3^{\text {rd }}$ edn. 1966 2016. Munchen, Berlin, Hamburg, Jena: Carl Hanser, Paul Parey, Weissdorn-Verlag.

Hoyle GL, Steadman KJ, Good RB, McIntosh EJ, Galea LME, Nicotra AB. 2015. Seed germination strategies: an evolutionary trajectory independent of vegetative functional traits. Frontiers in Plant Science 6: 113.

Hoyle GL, Venn SE, Steadman KJ, Good RB, McAuliffe EJ, Williams ER, Nicotra AB. 2013. Soil warming increases plant species richness but decreases germination from the alpine soil seed bank. Global Change Biology 19: 1549 1561.

Jaganathan GK, Dalrymple SE, Liu B. 2015. Towards an understanding of factors controlling seed bank composition and longevity in the alpine environment. Botanical Review 81: 70 103.

Jankowska-Blaszczuk M, Daws MI. 2007. Impact of red: far red ratios on germination of temperate forest herbs in relation to shade tolerance, seed mass and persistence in the soil. Functional Ecology 21: 10551062.

Jiménez-Alfaro B, Silveira FAO, Fidelis A, Poschlod P, Commander LE. 2016. Seed germination traits can contribute better to plant community ecology. Journal of Vegetation Science 27: 637645.

Jin Y, Qian H. 2019. V.PhyloMaker: an R package that can generate very large phylogenies for vascular plants. Ecography 42: 13531359.

Jumpponen A, Vare H, Mattson KG, Ohtonen R, Trappe JM. 1999.

Characterization of 'safe sites' for pioneers in primary succession on recently deglaciated terrain. Journal of Ecology 87: 98105.

Kammer PM, Mohl A. 2002. Factors controlling species richness in alpine plant communities: an assessment of the importance of stress and disturbance. Arctic, Antarctic, and Alpine Research 34: 398407.

Kaye TN. 1997. Seed dormancy in high elevation plants: implications for ecology and restoration. In: Kaye TN, Liston A, Love R, Luoma D, Meinke R, Wilson $\mathrm{M}$, eds. Conservation and management of native plants and fungi. Corvallis, Oregon, USA: Native Plant Society of Oregon, 115120.

Korner C. 2003. Alpine plant life: functional plant ecology of high mountain ecosystems. Berlin/Heidelberg, Germany: Springer.
Korner C, Paulsen J. 2004. A world-wide study of high altitude treeline temperatures. Journal of Biogeography 31: 713732.

Korner C, Paulsen J, Spehn E. 2011. A definition of mountains and their bioclimatic belts for global comparisons of biodiversity data. Alpine Botany 121: 7378 .

Le S, Josse J, Husson F. 2008. FactoMineR: an R package for multivariate analysis. Journal of Statistical Software 25: 118.

Leishman MR, Westoby M. 1994. The role of seed size in seedling establishment in dry soil-conditions experimental-evidence from semiarid species. Journal of Ecology 82: 249258.

Liu K, Baskin JM, Baskin CC, Bu H, Du G, Ma M. 2013. Effect of diurnal fluctuating versus constant temperatures on germination of 445 species from the eastern Tibet Plateau. PLoS ONE 8: e69364.

Lozano-Isla F, Benites-Alfaro OE, Pompelli MF. 2019. GerminaR: an R package for germination analysis with the interactive web application 'GerminaQuant for R'. Ecological Research 34: 339346.

Marcante S, Erschbamer B, Buchner O, Neuner G. 2014. Heat tolerance of early developmental stages of glacier foreland species in the growth chamber and in the field. Plant Ecology 215: 747758.

Marcante S, Sierra-Almeida A, Spindelbock JP, Erschbamer B, Neuner G. 2012. Frost as a limiting factor for recruitment and establishment of early development stages in an alpine glacier foreland? Journal of Vegetation Science 23: 858868

Marchand PJ, Roach DA. 1980. Reproductive strategies of pioneering alpine species: seed production, dispersal, and germination. Arctic and Alpine Research 12: 137146 .

Margreiter V, Pagitz K, Berg C, Schwager P, Erschbamer B. 2020. Pros and cons of using a standard protocol to test germination of alpine species. Plant Ecology 221: 10451067.

Martin AC. 1946. The comparative internal morphology of seeds. American Midland Naturalist 36: 513660

Mengersen K, Gurevitch J, Schmid CH. 2013. Meta-analysis of primary data. In: Koricheva J, Gurevitch J, Mengersen K, eds. Handbook of meta-analysis in ecology and evolution. Princeton: Princeton University Press, 300312.

Meyer SE, Monsen SB. 1991. Habitat-correlated variation in mountain big sagebrush (Artemisia tridentata ssp. vaseyana) seed germination patterns. Ecology 72: 739742 .

Moles AT, Ackerly DD, Webb CO, Tweddle JC, Dickie JB, Westoby M. 2005. A brief history of seed size. Science 307: 576580 .

Mondoni A, Daws MI, Belotti J, Rossi G. 2009. Germination requirements of the alpine endemic Silene elisabethae Jan: effects of cold stratification, light and GA3. Seed Science and Technology 37: 7987.

Mondoni A, Pedrini S, Bernareggi G, Rossi G, Abeli T, Probert RJ, Ghitti M, Bonomi C, Orsenigo S. 2015. Climate warming could increase recruitment success in glacier foreland plants. Annals of Botany 116: 907916.

Mondoni A, Rossi G, Orsenigo S, Probert RJ. 2012. Climate warming could shift the timing of seed germination in alpine plants. Annals of Botany 110: 155164

Nikolaeva MG, Rasumova MV, Gladkova VN. 1985. Pravocnik po prorascivanij pokojascichsja semjan (Reference Book on Dormant Seed Germination). Leningrad: Nauka, Leningrad Branch.

Nobis MP, Schweingruber FH. 2013. Adult age of vascular plant species along an elevational land-use and climate gradient. Ecography 36: 10761085.

Pagel M. 1999. Inferring the historical patterns of biological evolution. Nature 401: 877884

Parolly G, Rohwer JG. 2019. Schmeil-Fischen. Die Flora Deutschlands und angrenzender Lander, 97th edn. Wiesbaden: Quelle \& Meyer.

Pierce S, Luzzaro A, Caccianiga M, Ceriani RM, Cerabolini B. 2007. Disturbance is the principal $\alpha$-scale filter determining niche differentiation, coexistence and biodiversity in an alpine community. Journal of Ecology 95 : 698706

Pignatti S. 1982. Flora d'Italia, 3 vols. Bologna: Edagricole.

Pluess AR, Schutz W, Stocklin J. 2005. Seed weight increases with altitude in the Swiss Alps between related species but not among populations of individual species. Oecologia 144: 5561.

Pons TL. 2000. Seed responses to light. In: Fenner M, ed. Seeds: the ecology of regeneration in plant communities. Wallingford, UK: CABI, 237260. 
Poschlod P, Abedi M, Bartelheimer M, Drobnik J, Rosbakh S, Saatkamp A. 2013. Seed ecology and assembly rules in plant communities. In: van der Maarel E, Franklin J, eds. Vegetation Ecology. Chichester, UK: Wiley, 164202.

Pritchard HW, Tompsett PB, Manger KR. 1996. Development of a thermal time model for the quantification of dormancy loss in Aesculus hippocastanum seeds. Seed Science Research 6: 127135.

R Core Team. 2020. $R$ : a language and environment for statistical computing. v.4.0.3. Vienna, Austria: The R Foundation [WWW document] URL https:// www.r-project.org/.

Rodríguez R, Marticorena C, Alarcón D, Baeza C, Cavieres L, Finot VL, Fuentes N, Kiessling A, Mihoc M, Pauchard A. 2018. Catálogo de las plantas vasculares de Chile, Gayana. Botánica 75: 1430.

Rosbakh S, Baskin CC, Baskin JM. 2020a. Nikolaeva et al.'s reference book on seed dormancy and germination. Ecology 101: e03049.

Rosbakh S, Margreiter V, Jelcic B. 2020b. Seedlings of alpine species do not have better frost-tolerance than their lowland counterparts. Alpine Botany 130: 179 185.

Rosbakh S, Poschlod P. 2015. Initial temperature of seed germination as related to species occurrence along a temperature gradient. Functional Ecology 29: 5 14.

Royal Botanic Gardens, Kew. 2017. Seed information database (SID). Version 7.1. [WWW document] URL http://www.kew.org/data/sid [Accessed October 2017].

Saatkamp A, Affre L, Baumberger T, Dumas P-J, Gasmi A, Gachet S, Arène F. 2011. Soil depth detection by seeds and diurnally fluctuating temperatures: different dynamics in 10 annual plants. Plant and Soil 349: 331340.

Saatkamp A, Cochrane A, Commander L, Guja LK, Jiménez-Alfaro B, Larson J, Nicotra A, Poschlod P, Silveira FA, Cross AT. 2019. A research agenda for seed-trait functional ecology. New Phytologist 221: 17641775.

Satyanti A, Guja LK, Nicotra AB. 2019. Temperature variability drives withinspecies variation in germination strategy and establishment characteristics of an alpine herb. Oecologia 189: 407419.

Sayers RL, Ward RT. 1966. Germination responses in alpine species. Botanical Gazette 127: 1116.

Schneider CA, Rasband WS, Eliceiri KW. 2012. NIH Image to ImageJ: 25 years of image analysis. Nature Methods 9: 671 675 .

van der Schrier G, Efthymiadis D, Briffa KR, Jones PD. 2007. European Alpine moisture variability for 1800 2003. International Journal of Climatology 27: 415427.

Schutz W. 2002. Dormancy characteristics and germination timing in two alpine Carex species. Basic and Applied Ecology 3: 125134.

Schwienbacher E, Navarro-Cano JA, Neuner G, Erschbamer B. 2011. Seed dormancy in alpine species. Flora-Morphology, Distribution, Functional Ecology of Plants 206: 845856.

Shimono Y, Kudo G. 2005. Comparisons of germination traits of alpine plants between fellfield and snowbed habitats. Ecological Research 20: 189197.

Silvertown J, Franco M, McConway K. 1992. A demographic interpretation of Grime's triangle. Functional Ecology 6: 130136.

Simons AM. 2011. Modes of response to environmental change and the elusive empirical evidence for bet hedging. Proceedings of the Royal Society B-Biological Sciences 278: 16011609.

Smith SA, Brown JW. 2018. Constructing a broadly inclusive seed plant phylogeny. American Journal of Botany 105: 302314.

Sommerville KD, Martyn AJ, Offord CA. 2013. Can seed characteristics or species distribution be used to predict the stratification requirements of herbs in the Australian Alps? Botanical Journal of the Linnean Society 172: 187204.

Soyrinki N. 1938. Studien uber die generative und vegetative Vermehrung der Samenpflanzen in der alpinen Vegetation Petsamo-Lappland. I. Allgemeiner Teil. Annales Botanici Societatis Zoologicae-Botanicae Fennicae Vanamo 11: 1 311.
Taschler D, Neuner G. 2004. Summer frost resistance and freezing patterns measured in situ in leaves of major alpine plant growth forms in relation to their upper distribution boundary. Plant, Cell \& Environment 27: 737746.

Tester M, Morris C. 1987. The penetration of light through soil. Plant, Cell \& Environment 10: 281286.

Testolin R, Attorre F, Jiménez-Alfaro B. 2020. Global distribution and bioclimatic characterization of alpine biomes. Ecography 43: 779788.

The Plant List. 2013. Version 1.1. http://www.theplantlist.org/ [accessed June 2020].

Thompson JPM, Grime K. 1977. Seed germination in response to diurnal fluctuations of temperature. Nature 267: 147149.

Tudela-Isanta M, Fernández-Pascual E, Wijayasinghe M, Orsenigo S, Rossi G, Pritchard HW, Mondoni A. 2018. Habitat-related seed germination traits in alpine habitats. Ecology and Evolution 8: 150161.

Van Assche JA, Debucquoy KLA, Rommens WAF. 2003. Seasonal cycles in the germination capacity of buried seeds of some Leguminosae (Fabaceae). New Phytologist 158: 315323.

Van Assche JA, Vanlerberghe KA. 1989. The role of temperature on the dormancy cycle of seeds of Rumex obtusifolius L. Functional Ecology 3: 107115

Vandelook F, Janssens SB, Probert RJ. 2012. Relative embryo length as an adaptation to habitat and life cycle in Apiaceae. New Phytologist 195: 479487.

Vandelook F, Van de Vyver A, Carta A. 2019. Three phylogenetically distant shade-tolerant temperate forest herbs have similar seed germination syndromes. Folia Geobotanica 54: 7384.

Venable DL. 2007. Bet hedging in a guild of desert annuals. Ecology 88: 1086 1090.

Venable DL, Brown JS. 1988. The selective interactions of dispersal, dormancy, and seed size as adaptations for reducing risk in variable environments. American Naturalist 131: 360384.

Venn SE. 2007. Plant recruitment across alpine summits in south-eastern Australia. Melbourne, Australia: La Trobe University Bundoora.

Venn SE, Morgan JW. 2009. Germination characteristics of mountain celery Aciphylla glacialis (F. Muell.) Benth. (Apiaceae). Victorian Naturalist 126: 4 12.

Venn SE, Morgan JW. 2010. Soil seedbank composition and dynamics across alpine summits in south-eastern Australia. Australian Journal of Botany 58 : 349362.

Venn SE, Morgan JW, Lord JM. 2013. Foliar freezing resistance of Australian alpine plants over the growing season. Austral Ecology 38: 152161.

Verdú M, Traveset A. 2005. Early emergence enhances plant fitness: a phylogenetically controlled meta-analysis. Ecology 86: 13851394.

Vleeshouwers LM, Bouwmeester HJ, Karssen CM. 1995. Redefining seed dormancy: an attempt to integrate physiology and ecology. Journal of Ecology 83: 10311037.

Wagner I, Simons AM. 2009. Divergent norms of reaction to temperature in germination characteristics among populations of the arctic-alpine annual, Koenigia islandica. Arctic, Antarctic, and Alpine Research 41: 388395.

Walck JL, Hidayati SN, Dixon KW, Thompson K, Poschlod P. 2011. Climate change and plant regeneration from seed. Global Change Biology 17: 21452161.

Walder T, Erschbamer B. 2015. Temperature and drought drive differences in germination responses between congeneric species along altitudinal gradients. Plant Ecology 216: 12971309.

Wang Y, Wang J, Lai L, Jiang L, Zhuang P, Zhang L, Zheng Y, Baskin JM, Baskin CC. 2014. Geographic variation in seed traits within and among fortytwo species of Rhododendron (Ericaceae) on the Tibetan plateau: relationships with altitude, habitat, plant height, and phylogeny. Ecology and Evolution 4: 19131923.

Wright IJ, Reich PB, Westoby M, Ackerly DD, Baruch Z, Bongers F, Cavender-Bares J, Chapin T, Cornelissen JHC, Diemer M et al. 2004. The worldwide leaf economics spectrum. Nature 428: 821827. 